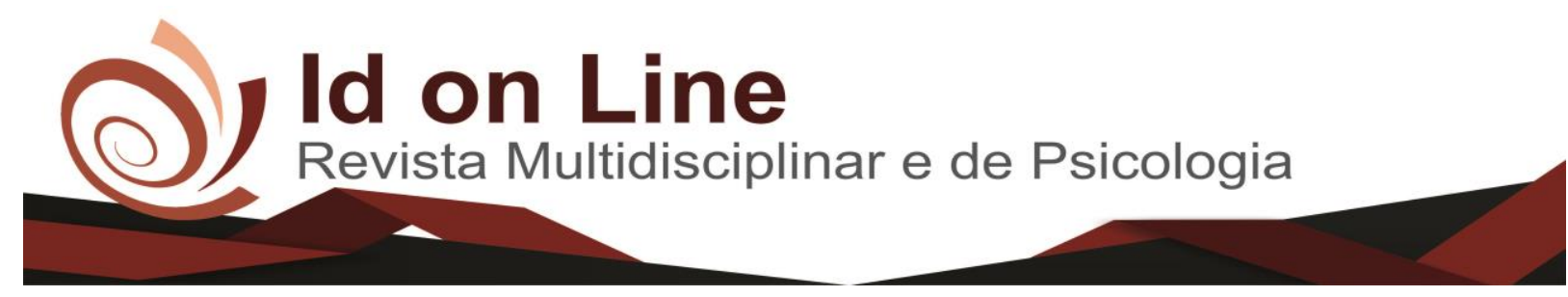

Comment

\title{
Reflexões sobre a importância do estímulo a prática da leitura
}

Maria Caroline dos Santos Freire ${ }^{l}$

\begin{abstract}
Resumo: Este trabalho foi realizado a partir de reflexões iniciadas na época do estágio supervisionado com o objetivo principal de analisar a importância da leitura na formação de alunos leitores garantindo ao indivíduo uma interação com a informação sistemática contribuindo para a construção de um cidadão crítico dos seus conhecimentos. Nesse sentido, buscou-se ressaltar a importância da leitura como ponto de processo abrangente, cuja linha de evolução permite a identificação de características especiais que definem momentos de crescimento da criança, desde o inicio da escolaridade, á integração ao ambiente familiar a escola. São muitos os cuidados que precisamos ter no trabalho que desenvolvemos com nossos alunos, utilizando as estratégias que valorizem cada oportunidade de crescimento, de fortalecimento das habilidades do futuro leitor. O mesmo foi realizado a partir de bibliografia de caráter qualitativo onde promovemos uma leitura reflexiva com os autores citados neste trabalho procurando estimular aos profissionais da educação um incentivo a praticas pedagógicas voltadas para a descoberta e imaginação da leitura da criança.
\end{abstract}

Palavras - chave: Leitura. Ensino. Aprendizagem. Prática pedagógica

\section{Reflections on the importance of encouraging reading practice}

\begin{abstract}
This work was based on reflections started at the time of the supervised internship with the main objective of analyzing the importance of reading in the formation of reading students, guaranteeing the individual an interaction with the systematic information contributing to the construction of a critical citizen of their knowledge. In this sense, it was sought to emphasize the importance of reading as a comprehensive process point, whose evolution line allows the identification of special characteristics that define moments of child growth, from the beginning of schooling, to integration into the family environment at school. There are many of the care we need to take on the work we do with our students, using strategies that value each opportunity for growth and for strengthening the skills of the future reader. The same was done from a qualitative bibliography where we promote a reflexive reading with the authors mentioned in this work trying to stimulate to the professionals of the education an incentive to pedagogical practices directed to the discovery and imagination of the reading of the child.
\end{abstract}

Keywords: Reading. Teaching. Learning. Pedagogicalpractice

\section{Introdução}

A formação de leitores é de suma importância, uma vez que a partir desse princípio o individuo garante uma melhor interação com a informação sistemática, o que contribui muito para a construção de um cidadão crítico capaz de questionar e argumentar sobre todo e qualquer fato.

\footnotetext{
${ }^{1}$ Graduanda do curso de Licenciatura em Pedagogia, pela Faculdade de Ciências Humanas do Sertão Central - FACHUSC. Contato: caroline_mcdsf@hotmail.com
} 
A ideia, portanto, de desenvolver o presente estudo surgiu a partir da observação do desenvolvimento de crianças em uma escola da rede municipal de Verdejante - PE. Nesse contexto, realizadas algumas observações nos levaram a crer que, o processo da leitura parece bastante defasado, pois crianças com idades avançadas ainda não haviam desenvolvido tal habilidade e, aquelas que já haviam desenvolvido pouco a praticavam! Desta forma, se faz necessário indagar e questionar: Como formar leitores nos anos iniciais do Ensino Fundamental?

Neste sentido, procuramos explicitar esta problemática, dar ênfase principalmente ao ato de ler, tentando mostrar da melhor forma possível o quanto esse hábito é fundamental.

A leitura é um importante instrumento para que o indivíduo possa garantir um espaço na sociedade, pois através dela formamos nossos conhecimentos e nos tornamos conhecedores do mundo ao qual vivemos.

Diante dessa indagação podemos Segundo os Parâmetros Curriculares Nacionais vol. 4 de Língua Portuguesa. Brasília. MEC/SEF (1997), entender que:

\begin{abstract}
A leitura é um processo no qual o leitor realiza um trabalho ativo de construção do significado do texto a partir dos seus objetivos, do seu conhecimento sobre o assunto, sobre o autor, de tudo que sabe sobre a língua: características do gênero, do portador, do sistema de escrita, e etc. Não se trata simplesmente de extrair informação da escrita, decodificando-a letra por letra, palavra por palavra. Trata-se de uma atividade que implica necessariamente, compreensão na qual os sentidos começam a ser constituídos antes da leitura propriamente dita. (PCNs, 1997, p. 33)
\end{abstract}

De acordo com esse parecer o objetivo do ensino de leitura na escola deve ser o de formar leitores competentes. Entende-se por leitor competente alguém que saiba selecionar dentre os textos de circulação social, aqueles que atendam as suas necessidades e que consiga ler não apenas o que está escrito explicitamente, mas também aquilo que está implícito. A reflexão impressa neste artigo buscou enfatizar o valor do processo da leitura na formação de alunos leitores e ressaltamos que por meio da mesma podemos formar cidadãos críticos, capazes de indagar sobre o mundo que o cerca. Sabe-se que a leitura é de suma importância e, o ato de ler é fundamental, seja na escola, em casa, ou em qualquer outro ambiente, não importa o lugar o que vale é render-se a uma boa leitura e se deixar levar nas vantagens que são oferecidas. Esse ato é maravilhoso, entretanto, várias pessoas não o possuem. É notável que as novas gerações 
não demonstram muito interesse em ler e quando o fazem é por necessidade e isso é preocupante pois, sendo assim tornam-se seres alienados.

Partindo desses princípios o objetivo principal deste artigo foi analisar a importância da leitura na formação de alunos leitores garantindo ao indivíduo uma interação com a informação sistemática contribuindo para a construção de um cidadão crítico dos seus conhecimentos. Comumente importante, ainda nessa mesma linha se faz necessário reconhecer o ato da leitura como sendo um processo de descobrimento da interação com o mundo; Demonstrar a importância em formar e garantir para a sociedade indivíduos leitores que façam do ato da leitura a construção do seu conhecimento e identificar que a leitura pode ser desenvolvida de forma prazerosa nos diversos ambientes.

Mas, afinal o que é ler? Ler é viajar utilizando apenas os olhos, podendo se utilizar da fala ou não, acima de tudo conhecendo mundos diferentes e enriquecendo o vocabulário, dando assim sentido ao que se está escrito. É fato, que as novas gerações têm demonstrado não apenas o desinteresse pela leitura, mas também a incapacidade de fazê-la coerentemente, compreendendo um texto em profundidade, o que inegavelmente limita o indivíduo em suas possibilidades de acesso ao conhecimento culturalmente construído.

Diante desse fato é tarefa urgente dos pais, da escola e sociedade em todos os níveis, buscar maneiras de estimular mais do que a capacidade de ler, o prazer pela leitura. É importante trabalhar leitura em todas as disciplinas com compreensão e interpretação de texto, pois o currículo pedagógico da escola independente da metodologia de cada professor tem como objetivo conhecimento dos conteúdos pelo aluno e a leitura deve ser vista em qualquer um dos currículos o uso da sua prática.

\section{Fundamentos para a formação da criança leitora}

A educação infantil é a primeira etapa da Educação Básica conforme legislação brasileira é nesta fase que a criança tem seus primeiros contatos com o mundo da leitura. Nessa etapa as mesmas realizam a leitura de imagem e iniciam seus primeiros rabiscos. Todavia, é através da observação e mediação do professor que a criança desenvolve o ato de ler e consequentemente de escrever. 
Entretanto, a maioria dos professores, no inicio de suas vidas como alunos, não vivenciaram situações que hoje são apontadas como fundamentais para a formação do leitor. Como resultado, encontramos muitos profissionais que embora conscientes da necessidade de ler e da sua responsabilidade na formação de alunos-leitores, sentem muita dificuldade em suas atuações e reconhecem inclusive que não são leitores. A época da vida mais propicia para a formação de hábitos de incorporação de conhecimentos básicos é a infância. Assim, quanto mais cedo se forma um leitor, melhor. Assim a escola, dadas às dificuldades das famílias, não pode perder a chance de fazer de seus alunos leitores já nos primeiros anos de escolarização. Essa é tarefa essencial e básica para o professor. Portanto, o trabalho de leitura na escola deve começar pelo professor para que ele se aproxime do livro, vença suas dificuldades pessoais, amplie seus conhecimentos e cultive o gosto pela leitura e pelas atividades com livros de literatura.

Para isso, retomamos uma ideia válida em todos os meios - O leitor se forma lendo uma verdade em qualquer situação. $O$ interesse pela leitura nasce da prática e da relação que seu conteúdo tenha com os interesses profissionais e pessoais. Na verdade o prazer de ler se estabeleceu quando a relação livro/leitor e quanto mais significativa for essa aproximação maior será o prazer de ler, fator decisivo para a formação do leitor. Na idade adulta, como é o caso do professor que necessita fortalecer sua competência leitora para chegar a ser entre outros efeitos positivos que se verificam quando o professor lê para o aluno, a questão da imitação. Imitação "refere-se ao ato de recriação, algo novo a partir daquilo que é observado nos outros; a oportunidade de realizar ações que estão além das capacidades individuais...”. Daí a grande importância da leitura pelo professor, dado o desejo natural de imitar o professor que lê. Estas orientações estão sempre presentes em qualquer rotina de aula por serem de extrema importância para o trabalho pedagógico de formação de leitores.

É importante ressaltar, que mesmo quando as crianças ainda não leem fluentemente, quando o professor conta histórias, lendo o texto escrito em voz alta, os alunos tem oportunidade de desenvolver diversas noções a respeito da língua escrita, que irão contribuir para o desenvolvimento do processo de alfabetização e letramento. O convívio com a modalidade escrita revela as diferenças entre o oral e escrito. Tanto que, quando as crianças são chamadas a recontar uma história, muitos tentam falar de um modo mais próximo as estruturas próprias da escrita. Isto acontece porque a criança nesse processo de formação leitora interage 
com diversidades de gêneros textuais, o que lhes garante a descoberta e a importância da leitura. Além disso, como as histórias provocam uma atividade mental intensa, a criança ouve de forma ativa, interage com o narrador e os personagens e reage fazendo antecipações, hipóteses, inferências.

É importante destacar que essa atividade mental forma habilidades importantes para compreensão de textos mais complexos. Quando se permite influências e participação durante a leitura de histórias, estimula o desenvolvimento dessas atividades. Questões preliminares imprescindíveis para assegurar um efetivo trabalho com leitura. Nesse sentido para que essa prática ocorra é necessário esforço para assegurar: convívio com livros, espaço físico agradável a leitura, poder expressar interpretações diante dos textos vistos e é muito importante a criança ter conhecimento sobre o porquê, o que e quando ler.

Portanto, estratégias que o professor deve utilizar para que a criança valorize cada oportunidade de crescimento, de fortalecimento das habilidades como futuro leitor. É muito importante o professor ler para os seus alunos, a magia que envolve todo o trabalho do contato com o livro de literatura, desde o de imagens até o livro com texto e somente texto, é algo tão profundo e tantas vezes indescritível, que se conhece somente quando se vivencia essa experiência. Quando trabalhamos com criança e instigamos nela o desejo e a curiosidade leitora, entramos num ambiente de parceria e de construção, que possivelmente é o maior beneficio que só conseguimos quando lemos em voz alta.

Outro fator a se destacar é quando a criança ouve uma história e aprecia suas ilustrações e estas têm experiências que farão sentido para ela, isso os revela a descoberta com sua realidade.

Para Cardoso (2012), aformação de leitores é assunto importante dentro do processo de construção da linguagem escrita, pois envolve o papel da escola, da sociedade e da família. O processo de leitura é muito mais que a decifração de um código, ler envolve uma serie de capacidades, que vão além da pura decodificação. Quem lê dessa forma não atribui significado ao texto e não compreende o que ler. Esse é um dos grandes problemas no Brasil: o analfabetismo funcional.

Outras capacidades que podemos refletir são compreensão, interação e interpretação. Para refletirmos sobre o que essas capacidades representam, pensaremos nas atitudes que um professor proficiente tem ao iniciar uma leitura. Deve escolher o que vai ler, levando em 
consideração algum motivo: necessidade, vontade, prazer. É importante conhecer o autor, o gênero que pertence o texto escolhido e suas principais características. Por meio dos seus conhecimentos prévios, consegue realizar algumas antecipações sobre o que vai ler. Durante a leitura, esse leitor também conseguira relacionar o texto que esta lendo com outros que já foram lidos anteriormente. Associar as imagens ao texto escrito.

Devemos considerar tudo isso. Então é possível trabalhar leitura com crianças bem pequenas, inclusive com bebes. Esse "trabalho" pode acontecer tanto em casa como na escola. A leitura precisa fazer parte da vida. É difícil esperar interesse pela leitura de uma criança que nasce vendo seus principais modelos pai e mãe, na maior parte dos casos não lendo.

Por isso o papel da escola nesse contexto torna-se ainda mais importante e complexo. É preciso mostrar desde cedo a estas crianças como desenvolver e utilizar as capacidades de leitura que um leitor proficiente possui.

A avaliação antes de tudo merece ser um processo de observação. Através da observação das brincadeiras percebe-se nas crianças os mais variados estímulos como pensamento crítico, formação cultural, ligação de ideias, convívio com pessoas diferentes e muitos outros aspectos que muitas vezes passam despercebidos.

Kramer (1998) sugere que se tenha um caderno de observação da turma, onde nesse deve conter os acontecimentos, as mudanças e as conquistas tanto dos alunos como dos próprios professores. No dia a dia o educador pode escolher um determinado grupo de alunos e fazer anotações individuais, informações que possam ser significativas no processo avaliativo. Além dessas técnicas Kramer (1998) indica o uso de calendários mensais que especifiquem as atividades a serem desenvolvidas, de modo em que a criança possa registrar informações sobre a atividade como dificuldades ou aprendizagens. Isso também pode ser feito através de gravuras. É sempre importante montar fichas de avaliação dos educandos, pois estas além de mostrar uma avaliação mais consistente, ainda direciona o trabalho pedagógico de maneira ao alcance de novos resultados satisfatórios.

No modelo clássico de avaliação o único objetivo que se tem é a classificação ou desclassificação do aluno. A avaliação na atualidade não tem mais tal sentido e é usada como instrumento para traçar novos objetivos. 
A partir do momento em que existe vida o ser humano passa a ser avaliado através de uma nota, um critério, um conceito, um valor e até mesmo um padrão. A sociedade em que vivemos nos leva a uma avaliação constante, a partir do momento em que vamos adquirindo e acumulando informações. Tais informações contribuem para o conhecimento de costumes, significados e linguagem de cada cultura. (MARTINEZ et. al, 2013, p.82)

Num processo avaliativo construtivista não existe o medo, angustias ou fracassos na avaliação, mas o que existe é uma compreensão do professor do que as crianças pensam. Nesse modelo o professor ver, registra e usa a avaliação como elemento mediador do trabalho pedagógico.

Seguindo então essa linha de raciocínio vale salientar: como avaliar através de práticas lúdicas em sala de aula? Sabe-se que a avaliação é um processo contínuo que acontece dentro de um sistema onde é levado em conta somente o que o aluno avançou ou aprendeu e não apenas suas incapacidades. Nesse sentido não acontece diferente quando se quer avaliar práticas lúdicas.

Em todo o processo metodológico deve existir avaliação para verificar se os objetivos foram ou não alcançados. O educador na proposição de atividades lúdicas deve sempre observar e se prender aos objetivos das práticas lúdicas, perceber se os objetivos estão sendo alcançados, de que forma estão sendo alcançados e quais dificuldades encontradas pelos alunos para a realização dessas práticas. É importante que o educador registre constantemente os fatos importantes ocorridos durantes as atividades lúdicas. É necessário que se tenha um olhar crítico para perceber a evolução dos educandos em cada atividade. No fim de cada atividade é sempre importante questionar aos alunos de maneira oral sobre aspectos presentes na brincadeira, no jogo, na música, na dança ou em qualquer que for a atividade lúdica. É necessário que o educador perceba a atividade lúdica e avalie de maneira política, social e cultural. É preciso que avalie de forma a respeitar as limitações de cada educando. Barbosa (2004) aponta o seguinte comentário:

Com instrumentos variados, utilizados em situações diversas, sempre autênticas e de aprendizagem, podemos recolher as informações necessárias para apreciar as capacidades das crianças, isto é, acompanhar o que elas já conhecem, o que sabem fazer (trabalhar com todos os domínios específicos, não priorizando as atividades linguísticas), as estratégias que usam para resolver problemas, suas formas de expressão, seu desenvolvimento motor, as estratégias interessantes etc (BARBOSA, 2004, p. 17). 


\title{
Estratégias de leituras na perspectiva dos estudiosos
}

\author{
Conforme Isabel Solé:
}

\begin{abstract}
As estratégias de leitura são as ferramentas necessárias para o desenvolvimento da leitura proficiente. Sua utilização permite compreender e interpretar de forma autônoma os textos lidos e pretende despertar o professor para a importância em desenvolver um trabalho efetivo no sentido da formação do leitor independente, crítico e reflexivo. (SOLÉ, 1988, p. 6)
\end{abstract}

Ainda nessa mesma discussão, Baldi(2009) ressalta que é de grande relevância utilizarse sempre das estratégias de leitura, pois diante do uso torna-se mais fácil o desenvolvimento do educando. Diante desta indagação, Baldi (2009) nos diz a respeito da leitura que: "Essa, como qualquer outra forma de arte (a pintura, a escultura, a música, o cinema, o teatro, a fotografia etc.), é capaz de nos tornar pessoas melhores, não só intelectual, mas emocionalmente, porque desperta o que de melhor existe em nós” (BALDI, 2009, p.7).

A prática da leitura desenvolve a autonomia intelectual do educando. Isto ele consegue através dos conhecimentos prévios de leitura. De acordo com De Pietri(2009).

\begin{abstract}
Uma possibilidade de considerar a relação leitor-texto é questionar que conhecimentos o leitor deve ter para compreender um texto e como esses conhecimentos são usados no momento da leitura, isto é, que estratégias são utilizadas pelo leitor, no momento em que lê, para construir o sentido do texto. Trata-se de questionar, portanto, os aspectos cognitivos envolvidos nessa atividade [...] $\mathrm{O}$ conhecimento linguístico, enquanto conhecimento prévio necessário para a compreensão de um texto, mostra-se de modo bastante claro, por exemplo, quando nos encontramos face a um texto escrito numa língua com a qual temos pouca ou nenhuma familiaridade. Conhecer os sons que compõem o sistema fonético dessa língua, bem como os modos como esses sons se organizam, isto é, seu sistema fonológico, além de conhecimentos do vocabulário, das regras de formação de palavras, das estruturas sintáticas e, também, de uso da língua, são conhecimentos linguísticos necessários para a compreensão de um texto. (DE PIETRI, 2009, p. $18,19)$.
\end{abstract}

Esses mesmos conhecimentos são colocados em jogo no momento de produzir e compreender um texto e é sem duvida essencial. Formar leitores competentes é o que se espera nos anos iniciais do Ensino Fundamental, porém isso não é tão fácil, pois a realidade do nosso país é o analfabetismo. Com isso as crianças não têm acesso à leitura, o que torna o trabalho da escola mais difícil, pois não será fácil incentivá-las a tornarem-se leitoras. 


\section{A Prática da leitura}

Embora ler seja um processo muito agradável e enriquecedor muitas pessoas não têm esse costume, desvalorizando as vantagens que um manual pode oferecer. Ensinar uma criança a ler não é uma questão simples, porém, não é impossível e se torna mais fácil com o auxílio dos pais, alias eles devem ser os primeiros motivadores para que as crianças tomem gosto pela leitura desde bem pequenas. Tanto os pais, professores e sociedade servem como espelhos para as crianças, pois ela tende a assimilar as pessoas que estão ao seu redor e com isso se os indivíduos que fazem parte do seu meio possuírem o hábito de ler a criança estará mais propicia a obter gosto pela leitura.Ler é fazer uma grande viagem rumo ao conhecimento desconhecidas, é ir a um lugar distante sem sair do lugar e principalmente se sentir como membro da história. De acordo com Solé (1988): “Aprender a ler significa aprender a encontrar sentido e interesse na leitura. Significa aprender a se considerar competente para a realização de tarefas de leitura e a sentir a experiência emocional gratificante da aprendizagem".

Diante disso podemos afirmar que quando aprendemos a ler encontramos o verdadeiro sentido que a leitura tem na nossa vida e a partir daí podemos realizar tarefas de leitura, o que antes era impossível, também podemos sentir a emoção gratificante da aprendizagem, pois a cada novo texto que lemos obtemos mais aprendizagem e conhecimentos vastos.

O leitor competente é aquele que está a todo tempo a procura de manuais para se manter sempre atualizado e com novos conhecimentos, um bom leitor entende o texto do início ao fim, até mesmo os aspectos que estão implícitos na leitura, cabe a ele ser ativo para saber desvendálos através das pistas que o texto revela. O leitor deve ser curioso e sem dúvidas ter objetivos para a leitura, para tornar-se agradável e se obtenha aprendizagem significativa. Sendo assim Isabel Solé (1988) nos coloca que:

\footnotetext{
Ensinar a ler exige a observação ativa dos alunos e da própria intervenção, como requisitos para estabelecer situações didáticas diferenciadas, capazes de se adaptar à diversidade inevitável da sala de aula. Isso pressupõe a renúncia aos estereótipos e às sequências homogêneas (ao "café para todos", todos os dias) em beneficio de uma prática educativa coerente no contexto em que se constrói (é o "café da manhã à lá carte”, com uma ampla variedade de cardápios).(SOLÉ, 1988, p. 32).
} 
O modelo de leitor oferecido pelo professor e as atividades propostas pelo mesmo para o ensino e a aprendizagem da leitura não são um luxo, mas uma necessidade. Nos dias de hoje a leitura é fundamental para o ser humano, pois a sociedade exige um leitor formado e competente e através das atividades propostas pelo professor sobre leitura o educando deverá formar seus conhecimentos para que possa se incluir em meio à sociedade. A sociedade espera que o aluno ao sair da escola saiba realmente ler, não só decodificando e sem entender o objetivo real do texto. Para que o aluno possa ler de maneira que compreenda o texto e faça críticas sobre o mesmo é necessário que o professor enquanto educador promova atividades em que os alunos tenham que perguntar, prever, recapitular para os colegas, opinar, resumir, comparar suas opiniões com relação ao que leram, dentre outros, para que através desses trabalhos os educandos possam também fomentar uma leitura inteligente. De acordo com Baldi (2009):

É preciso alimentar a imaginação de nossos alunos, compartilhar leituras com eles e oferecer-lhes experiências de fruição para que descubram os encantos da literatura como uma forma de arte que possibilita conhecerem melhor a si mesmos, ao mundo e aos que os cercam, para que se tornem pessoas mais sensíveis, mais críticas, mais criativas. (BALDI, 2009, p. 8)

É necessário, portanto, que o professor esteja sempre incentivando o aluno à leitura e alimentando a imaginação dos mesmos para que possam ler sem cessar, e principalmente possam ver as vantagens que temos quando possuímos o hábito de leitura. Devemos ver o ato de ler como uma ferramenta indispensável para os dias de hoje, pois tudo o que fazemos necessitamos da leitura. Pena que poucas pessoas leem, elas não sabem o quanto é bom conhecer histórias maravilhosas, principalmente as do passado, onde ficamos imaginando como seria se vivêssemos naquele período, além de alcançarmos muitos conhecimentos.

A aprendizagem da leitura é sem dúvida fundamental, pode ser um pouco complicada, mas pode-se ter certeza que no final de tudo esse processo é muito benéfico e satisfatório. Através do ato de ler nos leitores aprendemos palavras novas que agora passará a fazer parte do nosso vocabulário e também enriquecemos nossos conhecimentos a cada vez mais, a cada novo livro que lemos. Ler é um processo maravilhoso, quem bem sabe disso nunca deixa de ter um bom livro em mãos. 


\section{Os desafios na formação de alunos leitores}

Um dos múltiplos desafios a ser enfrentado pelo professor é mostrar aos alunos para que serve a leitura e qual o propósito dela. A todo o momento o educador se depara com situações difíceis em sala de aula com alunos que não querem aprender a ler, dizendo eles que não tem nenhuma vantagem nisso, não sabendo eles o que estão perdendo. Conforme (FREIRE, 2003, p.39): "Como eu, o analfabeto é capaz de sentir a caneta, de perceber a caneta e de dizer caneta. Eu, porém, sou capaz de não apenas sentir a caneta, de perceber a caneta, de dizer caneta, mas também de escrever caneta e, consequentemente, de ler caneta.

Nessa perspectiva podemos ver a grande importância de ler, pois através dela nós nos diferenciamos dos demais. Através dessa frase o aluno deveria analisar a real necessidade que temos em relação à leitura, pois ela é essencial para todos enquanto cidadãos preocupados com o futuro.

É preciso ressaltar que antes do aluno ler um texto este tenha conhecimentos sobre a leitura do mundo, para que quando passe a ler possa aplicar no texto seus conhecimentos prévios e entender melhor a leitura. Vale lembrar que através de uma boa leitura conhecemos grandes lições de vida. Segundo (FREIRE op.cit.p.25) "fui alfabetizado no chão do quintal de minha casa, à sombra das mangueiras, com palavras do meu mundo e não do mundo maior dos meus pais. O chão foi o meu quadro negro; gravetos, o meu giz." Essa lição de vida serve até como apoio para que crianças e jovens que não querem aprender a ler ou até mesmo escrever tomarem como exemplo, pois apesar de toda dificuldade esse autor que é conhecido por todos enfrentou todas as barreiras e conseguiu se tornar um ilustre membro da sociedade, diferentemente de algumas pessoas que tem todo meio de aprender e não atribuem o devido valor.

O hábito de leitura é quase que extinto no nosso mundo. Várias crianças e jovens frequentam a escola sem interesse de aprender, não se interessam sequer em aprender a fazer seu próprio nome, e futuramente conseguir fazer a leitura dele, o que é essencial para todos nos seres humanos tanto na escola como também fora dela. A desvalorização pelo ato de ler já se inicia com o desestimulo por parte dos pais, pois estes muitas vezes não mostram o estimulo necessário que as crianças necessitam para desenvolver o gosto pela leitura e em consequência desse fato quando essa criança começa a frequentar a escola o professor certamente terá mais dificuldade para despertar o gosto pela leitura no educando. De acordo com Solé (p. 18): 
Pode ler isto e, compreender e interpretar textos escritos de diversos tipos com diferentes intenções e objetivos contribui de forma decisiva para a autonomia das pessoas na medida em que a leitura é um instrumento necessário para que nos manejemos com certas garantias em uma sociedade letrada. (SOLÉ, 1988, p. 18)

Nessa perspectiva podemos afirmar que ler é com certeza uma boa vantagem para todos nós. Quando praticamos esse hábito que além de ser muito saudável e muito importante também obtemos novas aprendizagens e conhecimentos que irá nos ajudar em meio à sociedade a qual vivemos, embora que o hábito de ler seja visto por muitas pessoas como um processo enfadonho e que não traz nenhuma vantagem. Mas apesar de tantos desafios a quem diga que a leitura traz muitos benefícios para quem a pratica e é sem dúvida muito gratificante para todos que se envolvem nesse processo.

Nesse contexto, a escola necessita criar situações que motive à criança a leitura, oferecendo um ambiente eminentemente social, o espaço é então entendido com dimensões estratégicas e propicias a aprendizagem, o meio é fundamentalmente o ponto de partida, que desafie e promova atividades conjuntas entre parceiros numa abordagem afetiva que caminhando juntos oportunize a aprendizagem. A leitura é, portanto, uma prática social. Para Solé (1998) “O ensino da leitura deve garantir a interação significativa e funcional da criança com a língua escrita, como meio de construir os conhecimentos necessários para abordar as diferentes etapas da sua aprendizagem. (SOLÉ, 1998, p. 62).

A criança só desenvolverá a leitura se esta estiver motivado, portanto, é necessário que os professores criem situações de estímulo, através do diálogo, da brincadeira e da interação, e sobretudo, valorizar a língua materna como sistema interacional e dinâmico para trabalhar em sala de aula a leitura. Elementos como o cantinho da leitura são instrumentos valiosos, pois as crianças gostam de se apresentar. É preciso então que haja flexibilidade comunicativa entre professor e aluno e entre alunos. Para Bortoni (2008)

Refletir sobre a língua é trabalhar em uma perspectiva da gramática do uso, que leva o aluno a refletir sobre a língua dentro de contextos discursivos e pragmáticos, ajudando-o a pensar, a estrutura da língua, a produzir textos em suas diversas modalidades e a ampliar os usos pessoais. (BORTONI, 2008, p.38)

Para desenvolver a leitura na criança é preciso levá-las a ler o mundo através de músicas, de receitas, da informática, do filme, do gráfico, da notícia, do discurso político, enfim do 
mundo que ele conhece e vive. Ler é uma atividade que requer um controle consciente do processo da mente, de forma que, quanto maior for o nível de proficiência na leitura, maior será a probabilidade de desenvolvimento do pensamento reflexivo. A leitura só faz sentido para o leitor quando ele descobre as intenções, ele não pode adivinhar. À medida que a criança desenvolve o hábito da leitura é importante que elas possam ter acessos aos mais diferentes materiais, buscando de modo independente e aprendendo a ter responsabilidade. Cada material pode criar diferentes oportunidades de aprendizagem, portanto, é preciso que o professor seja inovador durante a leitura, podendo utilizar-se de diversos materiais de apoio como por exemplo: alfabeto móvel, brinquedos, esses materiais devem ser providenciados com antecedência e deve ser considerada as necessidades de todas as crianças

Tendo esse cuidado, o professor estará criando no aluno autonomia e garantindo-lhe o protagonismo. É importante frisar que essas estratégias devem ser continuas e não apenas uma vez ou outra porque percebe que o aluno não estar aprendendo. Existem algumas estratégias que podem ser usadas no dia a dia da sala de aula e que são bastante eficientes como: exposição de livros (cantinho da leitura), confecção de cartazes (com letras e imagens), leituras coletivas e individuais feitas pelos alunos, a leitura em voz alta feita pelo professor, um funcionário da escola, ou um familiar, entre outras.

\section{A Leitura numa perspectiva de ler, compreender e aprender}

Sempre que estamos fazendo uma leitura onde entendemos o real significado que o texto quis nos mostrar certamente podemos deduzir que fizemos uma boa leitura, tivemos uma ótima compreensão e com certeza aprendemos algo com ele.Quando estamos lendo um texto construímos uma interpretação. A interpretação é o nosso entendimento do texto, é quando entendemos o sentido que o texto quer nos passar. Vale lembrar que quando compreendemos algo que estamos lendo estamos construindo significado à leitura e isso nos torna um leitor ativo que compreende o texto em seus variados aspectos.

Conforme Solé(1988):

É claro que, quando escrevo, não posso pensar apenas em você; não seria correto esquecer que pode haver diferentes leitores, com distinta motivação, expectativas e 
conhecimentos com relação ao tema desse livro. Por isso tento elaborar um texto que "chegue" a todos os que os abordem, isto é, que possa ser compreendido e interpretado pelos seus potenciais leitores. O que não espero é que todos interpretem a mesma coisa, pois a compreensão que cada um realiza depende do texto que tem à sua frente, mas também depende muito de outras questões, próprias do leitor, entre as quais gostaria de ressaltar pelo menos as seguintes: o conhecimento prévio para abordar a leitura, os seus objetivos e a motivação com respeito a essa leitura. (SOLÉ, 1988, p. 40)

Percebe-se que, quando um autor elabora um livro ele deve pensar nos mais variados tipos de leitores que iram realizar a leitura do mesmo, para que assim todos possam construir sua interpretação do texto. Diz respeito também que cada leitor possui a sua interpretação de texto não podendo ser igual dos demais leitores que leem o mesmo manual.

A compreensão de texto está sempre ligada aos nossos conhecimentos prévios. Atribuímos ao texto o que já sabemos e tudo aquilo que faz ou fez parte da nossa vida, da nossa experiência. Sempre atribuímos à leitura as coisas que ouvimos ou vemos, esses aspectos são os nossos conhecimentos prévios. Conforme De Pietri (2009, p.21):

A compreensão do texto, portanto, é possível graças aos conhecimentos prévios que o leitor possui e à interação desses conhecimentos no momento da leitura. Essa interação se torna mais evidente quando, ao lermos um texto, nos deparamos com uma palavra desconhecida. Nesse momento, há pelo menos duas opções: ou o deixamos de lado e vamos procurar em outros lugares o significado da palavra (num dicionário, por exemplo), ou continuamos a lê-lo e tentamos, com base nas demais informações que esse texto apresenta, elaborar hipóteses sobre o significado daquela palavra. (DE PIETRI, 2009, p. 21)

Compreende-se que, para se alcançar uma boa compreensão durante a leitura de um texto e necessário que o leitor tenha objetivos naquela leitura, ele deve saber o que almeja alcançar com ela, para que a partir daí possa ter controle da leitura, pois de acordo com que vamos controlando a leitura certamente vamos compreendendo. Esse controle diz respeito aos obstáculos que encontramos durante a leitura e conseguimos superá-los.

Para que o indivíduo possa se envolver com uma atividade de leitura, é fundamental que este se sinta capaz de ler, de compreender o texto, tanto de forma autônoma como com a ajuda de pessoas mais experientes. No entanto crianças e jovens que não sabem ler acreditam que não são capazes de aprender e não se envolvem com os demais que já sabem, com vergonha talvez, o que não pode ocorrer, pois para que este possa aprender ele deve se sentir capaz e com certeza ser ajudado por pessoas mais experientes nesse ramo. E sem dúvida é necessário que este seja motivado, para que possa se entusiasmar mais. 
Vale lembrar a importância dos materiais oferecidos como suporte para leitura, devem ser atraentes e motivadores para incentivar o aluno a criar hábito pela leitura.

Diante do assunto tratado podemos dizer que ler é compreender e que compreender é um processo de construção de significados sobre o texto. E a partir daí lemos, compreendemos e com certeza aprendemos.

\section{Considerações finais}

O presente trabalho mostrou a importância e a necessidade do ato de ler, que é bem precário nos dias atuais, analisando a formação leitora da criança a partir de estratégias e práticas vivenciadas pelo professor. A sua finalidade foi dentre outras direcionar o olhar dos profissionais da educação rumo a função do hábito de ler. Enfatizou que nesse processo a escola, família e sociedade devem caminhar juntas com os objetivos de motivar o individuo a ler, proporcionando assim o acesso ao conhecimento e a formação crítica. A partir daí o individuo se sente auto motivado e apto a buscar o aprendizado e o aperfeiçoamento contínuo, o que passa pela formação de leitores competentes.

Neste sentido, o professor deve sempre estar em contato com a leitura, uma vez que ele é o facilitador de uma prática conhecedora, assim atraindo as crianças para este mundo de descobertas. É importante frisar que a criança ao ingressar no universo escolar já traz consigo uma bagagem de experiência adquirida com a família e comunidade, em relação à pré-leitura, contudo, cabe à escola aproveitar estes prévios conhecimentos para a prática de uma leitura cotidiana. Constatou-se então, que o futuro está na educação, especialmente na primeira etapa da Educação básica. Destacando que o hábito pela leitura é um processo constante que começa muito cedo em casa, aperfeiçoa-se na escola e continua pela vida inteira.

Dessa forma a leitura transformará a criança no seu dia-a-dia em leitor crítico, capaz de ler e entender o mundo e consequentemente lutar com dignidade para conquistar o seu espaço dentro da sociedade. Pois são vários os fatores que contribuem para desenvolver o interesse pela leitura de forma prazerosa, e se a criança nessa fase de desenvolvimento infantil, não vivenciar esse processo, ficará longe de fazer uma leitura do mundo que o cerca, podendo causar 
uma exclusão da sociedade. Neste caso a formação do professor é primordial, para que seja orientado a utilizar as melhores formas de estímulo à leitura.

\section{Referências}

BALDI, Elizabeth. Leitura nas séries iniciais: uma proposta para formação de leitores de literatura.Porto Alegre: Projeto, 2009.

BARBOSA, Maria Carmem Silveira. O acompanhamento das aprendizagens e a avaliação. Revista Pátio Educação Infantil. Ano II, nº.4, Abr/jul., 2004 p.17.

BRASIL. SECRETARIA DE EDUCAÇÃO FUNDAMENTAL. Parâmetros Curriculares Nacionais: Língua Portuguesa. Brasília, MEC/SEF, 1997.

BORTONI, Márcia Elizabeth. A construção da leitura e da escrita: do 6 ao 9 ano do ensino fundamental. São Paulo: Parábola Editorial, 2008.

CARDOSO, Bruna, P.A. A Práticas de linguagem oral e escrita: educação infantil. São Paulo: Editora, Anzol, 2012,p.16.

DE PIETRI Émerson. Práticas de leitura e elementos para a atuação docente.Rio de Janeiro: Ediouro, 2.ed.2009

FREIRE, Paulo. A importância do ato de ler.São Paulo: Moderna, 1 ed. 2003.

KRAMER, Sonia (org.); LEITE Maria Isabel Ferraz Pereira (org.). Infância e produção cultural. Campinas, SP: Papirus, 1998.

MARTINEZ, Juliana Zeggio; MOROSOW, Ivete. A Didática no Ensino e Avaliação da Aprendizagem em Língua Estrangeira. Curitiba, Intersaberes, 2013, p.82.

SOLÉ, Izabel. Estratégias de leitura. Porto Alegre: Artmed, 6.ed.1988.

Como citar este artigo (Formato ABNT):

FREIRE, Maria Caroline dos S. Reflexões sobre a importância do estímulo a prática da leitura. Id on Line Revista Multidisciplinar e de Psicologia, 2017, vol.11, n.38, p. 359-374. ISSN: 19811179 .

Recebido: 30.10 .2017

Aceito: 31.10 .2017 